\title{
Respiratory Syncytial Virus Induces Interleukin-10 by Human Alveolar Macrophages

\author{
Suppression of Early Cytokine Production and Implications for Incomplete Immunity
}

\author{
James R. Panuska, * Rocco Merolla, ${ }^{\ddagger}$ Nancy A. Rebert, ${ }^{*}$ Stephen P. Hoffmann, ${ }^{*}$ Paul Tsivitse, ${ }^{*}$ Nick M. Cirino, ${ }^{\$}$ \\ Robert H. Silverman, ${ }^{6}$ and John A. Rankin" \\ *Airway Disease Center, Department of Medicine, Case Western Reserve University, Cleveland, Ohio 44106; ${ }^{\ddagger}$ Fourth Pediatric Clinic of \\ Rome, Rome, Italy 1-00162; ${ }^{8}$ Department of Cancer Biology, the Research Institute of the Cleveland Clinic Foundation, Cleveland, \\ Ohio 44106; and "Division of Pulmonary Medicine, West Haven Veterans Hospital and Yale University School of Medicine, \\ New Haven, Connecticut 06519
}

\begin{abstract}
Respiratory syncytial virus (RSV) causes repeated infections thought to be due to an ineffective immune response. We examined the hypothesis that incomplete immunity may result, in part, from RSV-infected alveolar macrophage production of IL-10 which can interfere with the production of immunoregulatory cytokines. We also assessed whether RSV induced the expression of the 2 ', 5 ' oligoadenylate (2$5 A$ ) -dependent $R$ Nase $L$, an endoribonuclease involved in the antiviral activities of interferons. Human alveolar macrophages were exposed to medium (uninfected control), RSV, LPS, and RSV + LPS then were assessed for expression of the cytokines TNF- $\alpha, I L-1 \beta, I L-8, I L-10$, as well as 2-5A-dependent RNase $L$. LPS up-regulated the expression of protein and mRNA for all cytokines. RSV stimulated the protein levels of TNF- $\alpha$, did not alter IL-1 $\beta$, and decreased IL-8. RSV markedly stimulated protein expression of IL-10 and 2-5A-dependent RNase $L$. RSV had minor effects on the steady state mRNA levels of TNF- $\alpha$, IL-1 $\beta$, and IL-8, yet potently induced $\mathrm{IL-10}$. Cells costimulated with RSV + LPS demonstrated reduced protein and mRNA levels of TNF- $\alpha$, IL-1 $\beta$, IL-8 but synergistically increased IL-10 levels compared to RSV- or LPS-activated cells. Kinetic analysis indicated that RSV induced a delayed and sustained increase in IL-10 transcripts. Furthermore, RSV-infected al-

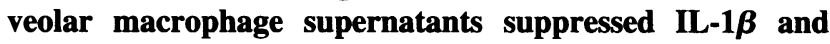
IL-8 production by LPS-stimulated alveolar macrophages as did recombinant IL-10. Anti-IL-10 neutralized these effects. These studies indicate that RSV is capable of suppressing production of early immunoregulatory cytokines through induction of $1 \mathrm{~L}-10$ perhaps mediated by $2-5 \mathrm{~A}-$ dependent RNase $L$ (or other endoribonucleases) accounting for the ineffective immune response to this virus. (J. Clin. Invest. 1995. 96:2445-2453.) Key words: IL-10 • IL-1 $\beta$ IL$8 \cdot$ TNF- $\alpha \cdot 2$ ',5' oligoadenylate-dependent RNase L
\end{abstract}

Address correspondence to James R. Panuska, Airway Disease Center, 2074 Abington Road, Department of Medicine, University Hospitals of Case Western Reserve University, Cleveland, OH 44106. Phone: 216368-1247; FAX: 216-368-1249; e-mail: jrp5@po.cwru.edu

Received for publication 13 February 1995 and accepted in revised form 10 July 1995.

\section{J. Clin. Invest.}

(C) The American Society for Clinical Investigation, Inc.

0021-9738/95/11/2445/09 \$2.00

Volume 96, November 1995, 2445-2453

\section{Introduction}

Respiratory syncytial virus (RSV), ' the major pathogen of infant's and young children's lungs, has been estimated to cause approximately one million deaths per year $(1,2)$. A formalininactivated vaccine for RSV proved deleterious (1), while a subunit vaccine is still under evaluation (3). Those results, coupled with the unusual propensity for RSV to cause repeated infections, suggests this virus may interfere with an effective immune response (1-4). An effective immune response requires antigen presentation and the ordered expression of cytokines to activate lymphocytes (5). Alveolar macrophages are the major immune-effector cells resident in the airways, the site of RSV infection in vivo, and may serve as antigen-presenting cells for this virus. Both in vivo and in vitro studies demonstrate that alveolar macrophages serve as a target for RSV infection, coexpress viral proteins, HLA-DR molecules, and biologically active cell-associated IL-1 $(6,7)$. Expression of these molecules by antigen-presenting cells serve as critical determinants to initiate an effective immune response (5).

We hypothesized that RSV disrupts the orchestrated production of cytokines by human alveolar macrophages contributing to an ineffective immune response. We further examined whether RSV stimulated expression of the $2^{\prime}, 5^{\prime}$ oligoadenylate (2-5A) -dependent RNase $\mathrm{L}$, an endoribonuclease induced by IFN with preference for UU and UA sequences in singlestranded RNA (8). Such sequences are present in the 3' untranslated regions of most cytokine messenger RNAs. Alveolar macrophages produce TNF- $\alpha$, IL- 6 , and GM-CSF after in vitro infection with RSV $(9,10)$. Although RSV infection in vivo induces alveolar macrophage expression of cell-associated TNF- $\alpha$ and IL- $1 \beta(6,7)$, in vitro studies demonstrate this virus: (a) causes only a transient increase in TNF- $\alpha$ mRNA, which is substantially less than that induced by LPS $(9)(b)$, does not stimulate expression of type $1(\alpha, \beta)$ IFN by differentiated macrophages, and $(c)$ increases the expression of an IL-1 inhibitor $(11,12)$. Thus, RSV stimulates both stimulatory and inhibitory cytokines that may regulate an effective immune response.

IL-10, originally described as cytokine synthesis inhibitory factor (13), can potently inhibit expression of cytokines by blood-derived monocytes (13-16). EBV, a DNA virus, has incorporated a homologue of the IL-10 gene thought critical to

\footnotetext{
1. Abbreviations used in this paper: 2-5A, 2',5' oligoadenylate; HPRT, hypoxanthine phosphoribosyl; pfu, plaque-forming unit; RSV, respiratory syncytial virus; RT, reverse transcription.
} 
latent infection by this virus (17). There is very little known about the effects of other viruses, particularly RNA viruses tropic for the lung, on IL-10 expression. The effects of RSV infection or LPS activation on human alveolar macrophage expression of IL-10 has not been described. LPS does stimulate alveolar macrophage expression of TNF- $\alpha$ and IL- $1 \beta$, which can induce IL- 8 production by both macrophages and lung epithelial cells (18). IL-8 is a specific, chemotactic agent for neutrophils (19). IL-10 has the potential to suppress IL-8, as well as other early cytokines (13-16). Finally, IL-10 can promote a $\mathrm{TH}_{2}$ helper cell response thus inducing specific antibodies which are known to be rapidly induced after RSV infection (20). Thus, IL-10 might have an important role in the pathogenic mechanisms regulating the lung immune response to RSV.

We examined alveolar macrophages exposed to medium (uninfected controls), RSV, LPS (as a maximal stimulus to cytokine expression), and the combination of RSV + LPS on the expression of selected stimulatory and inhibitory cytokines. We specifically focused on the primary cytokines TNF- $\alpha$ and IL- $1 \beta$, both of which induce expression of IL- $8(18,19)$. We also examined IL-10 which can inhibit the expression of all of these cytokines (14-16). The purpose of these studies was to determine if RSV altered the basal or LPS-stimulated cytokine expression by alveolar macrophages to provide possible insights into the immune response to RSV. Finally, TNF- $\alpha$ and IFN- $\beta$ can inhibit RSV replication in lung cells through an undefined mechanism $(21,22)$. We therefore examined the effects of RSV on the 2-5A-dependent RNase $\mathrm{L}$ which has the capacity to degrade viral and cytokine transcripts. The results of these studies are reported herein.

\section{Methods}

Donors. 20 healthy adult donors without a history of respiratory tract symptoms or use of medications or tobacco within the preceding four weeks underwent bronchoscopy and bronchoalveolar lavage after informed consent under a protocol approved by the Institutional Review Board of University Hospitals of Case Western Reserve University. Procedures for bronchoalveolar lavage were identical to those described previously $(9,21,23)$. Alveolar macrophages were isolated by adherence to plastic for $1 \mathrm{~h}$ in the presence of RPMI 1640 containing $10 \%$ (vol/vol) FBS (Hyclone, Logan, UT), $100 \mathrm{U} / \mathrm{ml}$ penicillin, $100 \mu \mathrm{g} /$ $\mathrm{ml}$ streptomycin, and $0.25 \mu \mathrm{g} / \mathrm{ml}$ amphotericin B (all supplements from Sigma Chemical Co., St. Louis, MO) (culture media). Adherent cells were $>95 \%$ viable as determined by acridine orange and ethidium bromide staining $(21,23)$. Greater than $97 \%$ of these cells expressed the macrophage-specific CD 68 antigen (Dako Corp., Carpinteria, CA) as determined by indirect immunofluorescent staining using methods previously described (7).

$R S V$ preparation. RSV strain $\mathrm{A}_{2}$ was obtained from Robert Chanock, National Institutes of Health, Bethesda, MD. Virus was propagated as previously described (21-23) in CV-1 cells ( $\mathrm{CCl}$ no. 70; American Type Culture Collection, Rockville, MD). Virus stocks were prepared from CV-1 monolayers harvested at $48 \mathrm{~h}$ after infection. Harvested cells were sonicated on ice two times (Artek Sonic Dismembrator; Fisher Scientific, Pittsburgh, PA), then made $100 \mathrm{mM}$ in $\mathrm{MgSO}_{4}, 1.6 \mathrm{mM}$ Hepes, $5 \mathrm{mM} \mathrm{NaCl}$, centrifuged at $200 \mathrm{~g}$ to remove cellular debris, and frozen at $-70^{\circ} \mathrm{C}$. Titer of viral stocks were determined using methods previously described $(21-23)$. Virus stocks contained undetectable levels of TNF- $\alpha$, IL- $1 \beta$, and IL-10. IL-8 levels were $<100 \mathrm{ng} / \mathrm{ml}$ while IL6 levels were $320 \pm 40 \mathrm{pg} / \mathrm{ml}$ (mean $\pm \mathrm{SD}, n=3$ separate determinations) using assays described below.

Cell culture conditions. Alveolar macrophages at $10^{6}$ cells $/ \mathrm{ml}$ were exposed to culture media, RSV (3 plaque-forming units [pfu]/cell), LPS from Escherichia coli (Lot No. 686709; Difco, Laboratories, Inc., Detroit, MI) (10 $\mu \mathrm{g} / \mathrm{ml})$, or both RSV and LPS (same doses) for $2 \mathrm{~h}$ at $37^{\circ} \mathrm{C}$ in $5 \% \mathrm{CO}_{2}$. Prior studies indicated that this dose of RSV maximally infects and induces alveolar macrophage cytokine expression (9). Ultraviolet light-inactivated RSV ( 3 pfu/cell) prepared as previously described (21) was used in selected experiments as described in the text to control for the effects of replication-incompetent virus as well as possible LPS contamination of virus stocks. Monolayers were then washed twice with media and incubated in fresh media at $37^{\circ} \mathrm{C}$ in $5 \% \mathrm{CO}_{2}$ for the times indicated in the text. Cultures were harvested, centrifuged at $400 \mathrm{~g}$, and cell-free supernatants in multiple aliquots were flash frozen in methanol dry ice and stored at $-70^{\circ} \mathrm{C}$ until analyzed.

Cell monolayers were overlaid with $4 \mathrm{M}$ guanidine isothiocyanate containing $0.1 \mathrm{M} \beta$-mercaptoethanol, harvested by cell scraping, and homogenized by 20 strokes through a syringe with a 20 -gauge needle. RNA was extracted with phenol/chloroform exactly as described by Chomczynski and Sacchi (24) and stored at $-70^{\circ} \mathrm{C}$ until further analyzed.

Cytokine assays. Parallel supernatant aliquots were analyzed in a blinded fashion for TNF- $\alpha$, IL- $1 \beta$, and IL-10 by the Mediator Core Laboratory of the Airway Disease Center and for IL-8 by one of us ( $\mathrm{J}$. A. Rankin). TNF- $\alpha$ was analyzed by RIA (Amersham International, Little Chalfont, UK) and IL- $1 \beta$ by ELISA ( $R$ \& D Systems, Minneapolis, $\mathrm{MN}$ ) using methods previously described $(6,9)$. IL-10 was determined by ELISA (Biosource International, Camarillo, CA) with antibodies that do not cross-react with IL- $1 \alpha$, TNF- $\alpha$, IL-8, IL-2, or IFN. IL- 8 was determined by ELISA using antibodies and methods previously described $(25,26)$. IL-6 levels were determined by ELISA (R\&D Systems, Minneapolis, MN). A neutralizing mAb to IL-6 was obtained from R\&D Systems and recombinant IL-6 was obtained from BioSource International. A neutralizing rat antibody to human IL-10 was obtained from Pharmingen, San Diego, CA, while recombinant human IL-10 was obtained from Genzyme Corp. Cambridge, MA.

RNA analysis. Total RNA was quantitated by spectrophotometry as well as densitometry of ethidium bromide-stained agarose-formaldehyde gels $(0.9 \%$, wt/vol ). Equal amounts of RNA were transferred to Genescreen (NEN Research Products, Boston, MA) membranes by capillary blot, cross-linked with ultraviolet light (UV Stratalinker ${ }^{\circledR}$, Stratagene Inc., La Jolla, CA), and baked at $80^{\circ} \mathrm{C}$ for $2 \mathrm{~h}$.

Northern blot analysis was performed using methods previously described $(9,23,27)$. Briefly, Genescreen membranes were prehybridized with $35 \%$ formamide, $1 \times$ Denhardt's, $2 \times$ SSC, $0.5 \%$ SDS, and $50 \mu \mathrm{g} / \mathrm{ml}$ heat-denatured salmon sperm DNA (prehybridization buffer) at $42^{\circ} \mathrm{C}$ for $4 \mathrm{~h}$. Hybridization was performed with ${ }^{32} \mathrm{P}$-labeled cDNA probes for human TNF- $\alpha$, the 560-bp HindIII cDNA fragment from pAW739 (No. 53163; American Type Culture Collection), IL$1 \beta$, the 570-bp BamHI-HindIII fragment from $\mathrm{p} \Delta .11$, originally from Peter LoMedico (Hoffman La Roche, Inc., Nutley, NJ); IL-8, a plasmid containing the full-length coding region, from Tiezo Yoshimura (National Cancer Institute, Bethesda, MD); IL-10, a plasmid containing the full-length coding region, from Jan E. de Vries (DNAX, Palo Alto, CA); a cDNA for human 18 S RNA (provided by Robert Silverman, Cleveland Clinic Foundation, Cleveland, $\mathrm{OH}$ ); and glyceraldehyde phosphate dehydrogenase (GAPDH). cDNA probes were labeled by random primer extension (Boehringer Mannheim, Indianapolis, IN) and specific activities ranged from $3 \times 10^{8}$ to $5 \times 10^{9} \mathrm{cpm} / \mu \mathrm{g}$. Membranes were hybridized at $42^{\circ} \mathrm{C}$ for $16 \mathrm{~h}$ with agitation in prehybridization media without salmon sperm DNA containing $10 \mathrm{mM}$ EDTA. Membranes were washed sequentially at $25^{\circ} \mathrm{C}$ in $2 \times \mathrm{SSC}, 0.5 \%$ SDS, $1 \times$ $\mathrm{SSC}, 0.5 \% \mathrm{SDS}$, and finally at $60^{\circ} \mathrm{C}$ in $0.1 \times \mathrm{SSC}, 0.5 \%$ SDS then autoradiographed. Previously bound probes were removed from membranes by incubation in $200 \mathrm{ml}$ of $0.1 \times$ SSC, $0.5 \%$ SDS, $0.1 \times$ Denhardt's, $0.2 \mathrm{mM}$ EDTA, and $0.05 \%$ sodium pyrophosphate with agitation at $75^{\circ} \mathrm{C}$ for $2 \mathrm{~h}$.

Purified RNA, prepared as described above, was also analyzed by reverse transcription (RT) and PCR amplification using methods de- 
Table I. Primers Used for Reverse Transcription and Polymerase Chain Amplification

\begin{tabular}{clc}
\hline Gene & \multicolumn{1}{c}{ Primer sequence* } & Position in gene \\
\hline \multirow{2}{*}{ IL-8 } & Upstream 5'-ATT TCT GCA GCT CTG TGT GAA GGT GC-3' & $144-169$ \\
& Downstream 5'-TTG TGG ATC CTG GCT AGC AGA C-3' & $872-893$ \\
IL-10 & Upstream 5'-CTG AGA ACC AAG ACC CAG ACA TCA A-3' & $323-349$ \\
& Downstream 5'-CAA TAA GGT TTG TCA AGG GGC TGG GTC-3' & $649-674$ \\
HPRT & Upstream 5'-CGA GAT GTG ATG AAG GAG ATG G-3' & $236-257$ \\
& Downstream 5'-GGA TTG TAC TGC CTG ACC AAG G-3' & $528-549$ \\
\hline
\end{tabular}

* Based on references of sequences deposited in Genbank. Ascession numbers: IL-8, M26383; IL-10, M57627; HPRT, M31642.

scribed by the manufacturer (Perkin-Elmer Cetus, Norwalk, CT). Purified RNA ( $500 \mathrm{ng}$ ) was treated with $50 \mathrm{U}$ of reverse transcriptase in a final vol of $20 \mu \mathrm{l}$ of buffer containing $10 \mathrm{mM}$ Tris- $\mathrm{HCl}, \mathrm{pH} 8.3,50$ $\mathrm{mM} \mathrm{KCl}, 5 \mathrm{mM} \mathrm{MgCl} 2,1 \mathrm{mM}$ dNTPs, $20 \mathrm{U}$ RNase inhibitor, and 2.5 $\mu \mathrm{M}$ random hexamers (all reagents from Perkin-Elmer Corp.). Reactions were performed at $42^{\circ} \mathrm{C}$ for $45 \mathrm{~min}$. In each experiment, control samples containing RNA but without RT were performed to insure that amplification did not occur from residual genomic DNA.

PCR reactions were performed in 50- $\mu \mathrm{l}$ reaction vol containing 10 $\mathrm{mM}$ Tris, $\mathrm{pH} 8.3,50 \mathrm{mM} \mathrm{KCl}, 0.7 \mathrm{mM}$ dNTPs, $2 \mathrm{mM} \mathrm{MgCl}_{2}$ for IL10 , and hypoxanthine phosphoribosyl (HPRT), $4 \mathrm{mM} \mathrm{MgCl} 2$ for IL-8, and $25 \mathrm{U} / \mathrm{ml} \mathrm{Amplitac}{ }^{\circledR}$ DNA polymerase (Perkin-Elmer Cetus). Primer concentrations were $0.15 \mu \mathrm{M}$. The primers used for IL-8, IL-10, and HPRT are shown in Table I. Reactions were overlaid with mineral oil and processed by melting for $1 \mathrm{~min}$ at $95^{\circ} \mathrm{C}$, annealing for $2 \mathrm{~min}$ at 58 , 55 , and $62^{\circ} \mathrm{C}$ for $\mathrm{IL}-8, \mathrm{IL}-10$, and HPRT, respectively, and extending for $3 \mathrm{~min}$ at $72^{\circ} \mathrm{C}$ for the cycle numbers listed in the text. One additional 15 min cycle was used for elongation at $72^{\circ} \mathrm{C}$.

The PCR products (10- $\mu$ l aliquots) were analyzed by agarose gel electrophoresis and restriction analysis based on sequences deposited in Genbank (Table I). Initial experiments were performed to insure the amplified products were specific for IL-8, IL-10, and HPRT. Furthermore, RT-PCR reactions were optimized to yield single products on agarose gel electrophoresis. IL-8 yielded a product of 749 bp that, after restriction analysis with EcoRI, yielded the predicted fragments of 501 and $201 \mathrm{bp}$. IL-10 yielded a product of $351 \mathrm{bp}$ that, after restriction analysis with Taq1, yielded products of 259 and $92 \mathrm{bp}$. HPRT yielded a product of 314 bp that, after restriction analysis, with HindII yielded the predicted fragments of 177 and 137 bp (not shown).

PCR amplification of RT reaction products were directly proportional to starting RNA concentrations in the range of $100-500 \mathrm{ng}$ for IL-8, IL-10, and HPRT. The amount of PCR product varied with cycle number, therefore aliquots of $\mathrm{PCR}$ products were removed at 26,29 , and 31 cycles and were analyzed by densitometry of negative photographs of ethidium bromide-stained gels. Values that increased linearly with cycle number were used for comparisons. In each experiment, parallel and equal aliquots $(5 \mu \mathrm{l})$ of the RT reaction were amplified by PCR in the presence of primer pairs for IL-8, IL-10, and HPRT. Agarose gels contained $10-\mu \mathrm{l}$ aliquots of the PCR reaction products as well as a standard curve of pEAR DNA ranging from 1,000-62.5 ng concomitantly stained with ethidium bromide. Photographs of gels were obtained with Kodak 55 film (Eastman Kodak Co., Rochester, NY) and scanned by densitometry (SciScan ; US Biochemical Corp., Cleveland, $\mathrm{OH}$ ).

Western blots. Western blots were performed as previously described (27). Cell lysates of alveolar macrophages were harvested by scraping into SDS buffer, adjusted to $75 \mu \mathrm{g} / \mathrm{sample}$, and electrophoresed on SDS $15 \%(\mathrm{wt} / \mathrm{vol}$ ) polyacrylamide gels. After electrophoresis, proteins were transferred to nitrocellulose membranes in a buffer containing $150 \mathrm{mM}$ glycine, $50 \mathrm{mM}$ Tris, $\mathrm{pH} 8.3,0.025 \%$ (wt/vol) SDS, and $15 \%$ (vol $/$ vol) methanol (transfer buffer). Transfer was performed for at $4^{\circ} \mathrm{C}$ at $500 \mathrm{~mA} / \mathrm{gel}$ for $1.5 \mathrm{~h}$. Membranes were then blocked for $2 \mathrm{~h}$ in $5 \%$ (wt/vol) Carnation powdered milk, 1\% (wt/vol) BSA in a buffer containing $125 \mathrm{mM} \mathrm{NaCl}, 0.1 \%$ (vol/vol) Tween 20 , and $100 \mathrm{mM}$ Tris, $\mathrm{pH} 7.0$ (blocking buffer). A primary mouse $\mathrm{mAb}(5 \mu \mathrm{g} / \mathrm{ml}$ in blocking buffer) specific for the human 2-5A-dependent RNase $\mathrm{L}$ was added for $2 \mathrm{~h}$ at $25^{\circ} \mathrm{C}(28)$. Blots were then washed four times in blocking buffer and reacted for $1 \mathrm{~h}$ at $25^{\circ} \mathrm{C}$ with a rabbit anti-mouse second antibody coupled to peroxidase (1:1,000 dilution in blocking buffer) (Amersham Corp.). Blots were washed four times with blocking buffer then overlaid with substrate (Amersham Corp.) and exposed to film (XAR 5; Eastman Kodak) for 10 min.

Western blots of IL-10 were performed on cell lysates + supernatants (75 $\mu \mathrm{g} / \mathrm{sample})$ resolved on SDS $15 \%(\mathrm{wt} / \mathrm{vol})$ polyacrylamide gels followed by transfer to Immobilon PVDP membranes (Millipore Corp., Bedford, MA) at $4^{\circ} \mathrm{C}$ at $70 \mathrm{~V}$ for $16 \mathrm{~h}$ in transfer buffer. Membranes were blocked as above, and reacted with a goat anti-human IL10 antibody ( $R$ \& D Systems). Membranes were then reacted with a rabbit anti-goat antibody coupled to peroxidase and developed with substrate (LumiGlo@ Chemiluminescent reagent; Kirkegaard \& Perry Laboratories, Inc., Gaithersberg, MD) as described by the manufacturer.

Statistics. Results shown are mean \pm SEM or SD as indicated in the text. Data were assessed for normal distribution with the National Institutes of Health sponsored CLINFO project. Differences between medians were assessed by Wilcoxon signed rank tests while differences between means of normally distributed results were analyzed by Student's $t$ tests and were considered significant with $P<0.05$.

\section{Results}

Alveolar macrophage supernatant cytokine levels. The accumulation of TNF- $\alpha$, IL- $1 \beta$, IL-8, and IL-10 in aliquots of supernatants from alveolar macrophages exposed to medium (uninfected controls), RSV ( 3 pfu/cell, a dose shown previously to maximally induce TNF- $\alpha, 9)$, LPS $(10 \mu \mathrm{g} / \mathrm{ml})$, and RSV + LPS (same doses) were examined. Results are shown in Fig. 1. Alveolar macrophages incubated in medium alone (control, $C$ ) for $24 \mathrm{~h}$ yielded low supernatant levels of TNF- $\alpha$, IL- $1 \beta$, and IL-10 while constitutive levels of IL- 8 were comparable to previous studies $(25,26,29,30)$. Alveolar macrophages infected with RSV for $2 \mathrm{~h}(R)$, then washed and cultured in fresh medium for $22 \mathrm{~h}$, had increased supernatant levels of TNF- $\alpha$ and IL-10 compared to controls. In contrast, RSV infection did not alter IL- $1 \beta$ levels and actually suppressed IL-8 levels, albeit only by $\sim 35 \%(P<0.05)$, compared to controls. LPS $(L)$ markedly stimulated TNF- $\alpha$, IL- $1 \beta$, and IL-8 production compared to controls but yielded IL-10 levels similar to RSV-exposed cells. Unexpectedly, cells exposed to RSV + LPS $(R$ $+L)$ demonstrated significantly $(P<0.05)$ reduced levels of TNF- $\alpha$, IL- $1 \beta$, and IL-8 but markedly increased levels of IL- 


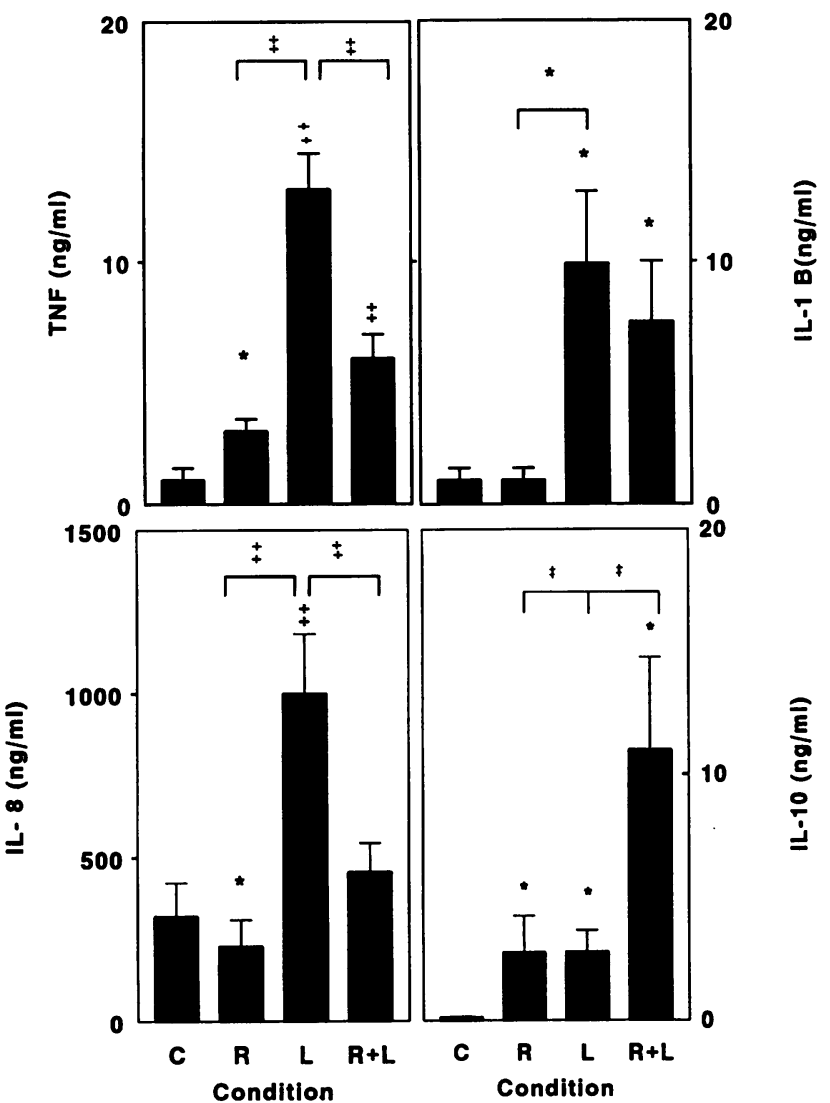

Figure 1. TNF- $\alpha$ (upper left), IL-1 $\beta$ (upper right), IL-8 (bottom left), and IL-10 (bottom right) protein levels in aliquots of alveolar macrophage supernatants. Alveolar macrophages $\left(10^{6}\right.$ cells $\left./ \mathrm{ml}\right)$ were incubated in culture medium for $24 \mathrm{~h}(C)$; exposed to RSV ( $3 \mathrm{pfu} /$ cell for $2 \mathrm{~h})(R)$; exposed to LPS ( $10 \mu \mathrm{g} / \mathrm{ml}$ for $2 \mathrm{~h}$ ) $(L)$; or exposed to LPS $+\mathrm{RSV}$ ( same doses for $2 \mathrm{~h})(R+L)$ as indicated. Alveolar macrophages were then placed into fresh media and incubated for $22 \mathrm{~h}$. Supernatants were harvested, centrifuged at $400 \mathrm{~g}$ for $10 \mathrm{~min}$, aliquoted, and flash frozen at $-70^{\circ} \mathrm{C}$. All aliquots were analyzed in duplicate or triplicate for TNF- $\alpha$ by RIA, and for IL- $1 \beta$, IL- 8 , and IL- 10 by ELISA as described in Methods. Results shown are mean \pm SEM with $n=8$ for IL- $1 \beta, n=13$ for TNF- $\alpha$ and IL-8, and $n=5$ for IL-10. $* P<0.05$ compared to controls and ${ }^{\ddagger} P<0.01$ by Wilcoxon rank sum with brackets indicating comparisons between conditions.

10 compared to cells exposed to LPS alone. Thus, RSV differentially altered cytokine expression by alveolar macrophages yielding a selective increase in TNF- $\alpha$ and IL-10 yet suppressed the LPS-induced production of TNF- $\alpha$, IL- $1 \beta$, and IL-8. RSV + LPS increased IL-10 expression in a synergistic fashion compared to RSV or LPS alone. Western blots confirmed that RSV markedly induced the expression of a $17-\mathrm{kD}$ band that specifically reacted with IL-10 (not shown) consistent with prior studies $(13,14,31)$.

Effects of RSV, ultraviolet light-inactivated RSV, and/or LPS on alveolar macrophage protein expression. It was possible that RSV inhibited alveolar macrophage protein synthesis thus interfering with cytokine expression. To examine this possibility, alveolar macrophage cell lysates were prepared at 6,12 , and $24 \mathrm{~h}$ after exposure to medium, RSV, LPS, or RSV + LPS (same doses as above) and analyzed by SDS PAGE. Abundant cell lysate proteins detected by Coomassie blue staining did not reveal a virus or LPS-induced alteration in protein amounts through $24 \mathrm{~h}$ (not shown). Thus, RSV did not yield a generalized suppression of protein expression suggesting other mechanisms might account for these alterations in cytokine expression.

To assess if these effects were mediated by infectious RSV, ultraviolet light-inactivated RSV (same dose as above prepared as previously described, 21 ) was added to alveolar macrophages for $2 \mathrm{~h}$, replaced with fresh medium, and the supernatants were harvested after $22 \mathrm{~h}$. TNF- $\alpha$, IL- $\beta$, IL-8, and IL-10 levels were within $\pm 10 \%$ of the levels seen with cells exposed to control medium $(n=3)$. Furthermore, RSV stocks contained undetectable TNF- $\alpha$, IL- $1 \beta$, IL-10, and IL- 8 levels of $\sim 100 \mathrm{ng} / \mathrm{ml}$, less than constitutive levels produced by alveolar macrophages (Fig. 1). RSV stocks did contain IL-6 at $\sim 320 \mathrm{pg} / \mathrm{ml}$, and the effect of IL-6 on alveolar macrophage cytokine expression is assessed below.

Steady state mRNA levels of $T N F-\alpha, I L-1 \beta, I L-8$, and $I L$ 10. To assess whether RSV directly altered mRNA transcripts for these cytokines, Northern blot analyses were performed on total pooled RNA harvested at $24 \mathrm{~h}$ after stimulation from the first eight sequential donors whose supernatant cytokine results were shown in Fig. 1. Northern blots were probed sequentially with ${ }^{32} \mathrm{P}$-cDNA probes for TNF- $\alpha, \mathrm{IL}-1 \beta, \mathrm{IL}-8$, and the $18 \mathrm{~S}$ form of ribosomal RNA, Fig. $2 A$. Alveolar macrophages exposed for $24 \mathrm{~h}$ to medium alone (control, $C$ ) yielded undetectable steady state transcript levels of TNF- $\alpha$, and low levels of IL-1 $\beta$ and IL-8. RSV $(R)$ minimally increased the steady state mRNA levels of TNF- $\alpha$, IL-1 $\beta$, and IL-8. RSV + LPS $(R+L)$ yielded lower steady state transcript levels of TNF- $\alpha, \mathrm{IL}-1 \beta$, and IL-8 compared to cells exposed to RSV. Wells not loaded with RNA (blank, $B$ ) indicated the absence of nonspecific binding of ${ }^{32} \mathrm{P}$-labeled cDNA probes. LPS $(L)$ markedly increased transcript levels for each of these cytokines and resulted in higher levels than cells exposed to RSV + LPS. Blots probed for expression of $18 \mathrm{~S}$ ribosomal RNA indicated equivalent RNA loading.

In contrast, IL-10 expression by alveolar macrophages exposed to these stimuli for $24 \mathrm{~h}$ differed strikingly. IL-10 and GAPDH mRNA steady state levels analyzed by Northern blots are shown in Fig. $2 B$ (pooled RNA from the five donors whose IL-10 protein levels were shown in Fig. 1). Alveolar macrophages incubated in medium alone (control, $C$ ) had undetectable IL-10 while those exposed to RSV $(R)$, LPS $(L)$, and RSV + LPS $(R+L)$ demonstrated increased IL-10 transcripts. (top). Reprobing this blot for GAPDH mRNA, as a constitutive housekeeping gene, demonstrated slightly lower GAPDH levels in LPS and RSV + LPS lanes (bottom).

Densitometry of TNF- $\alpha$, IL- $1 \beta$, and IL-8 normalized to $18 \mathrm{~S}$ rRNA as well as IL-10 normalized to GAPDH are shown in Fig. 2 C. RSV increased steady state levels of IL-8 and IL-10 compared to controls whereas LPS increased the levels of all cytokines. In contrast, RSV + LPS selectively stimulated IL10 levels while yielding markedly reduced levels of TNF- $\alpha$, IL$1 \beta$, and IL- 8 compared to LPS-stimulated cells alone. Thus RSV alone, or in combination with LPS, stimulated IL-10 mRNA levels.

Kinetics of expression of TNF- $\alpha, I L-8, I L-10$, and HPRT. We have previously shown that RSV induces a rapid increase in TNF- $\alpha$ with a maximum increase at $2 \mathrm{~h}$ after viral exposure that returned to baseline by $8 \mathrm{~h}$ after viral exposure (9). TNF$\alpha$ can induce expression of IL-8, and a prior study demonstrated 
A

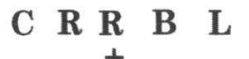
$\stackrel{+}{\mathbf{L}}$
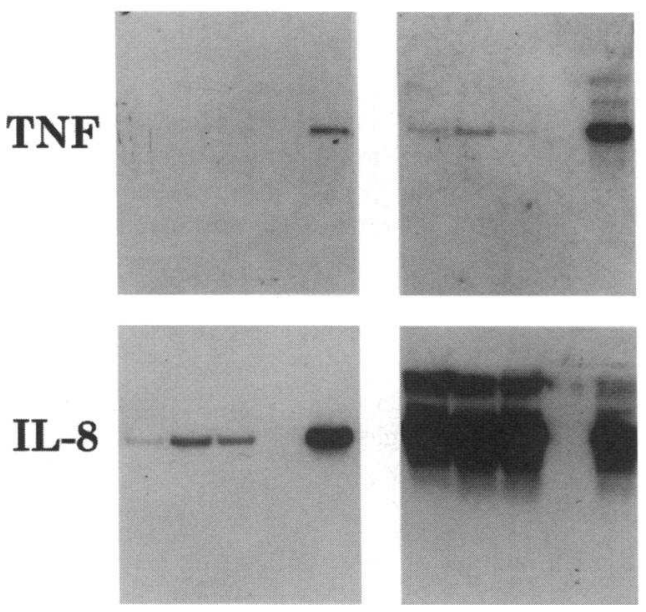

18S rRNA

C

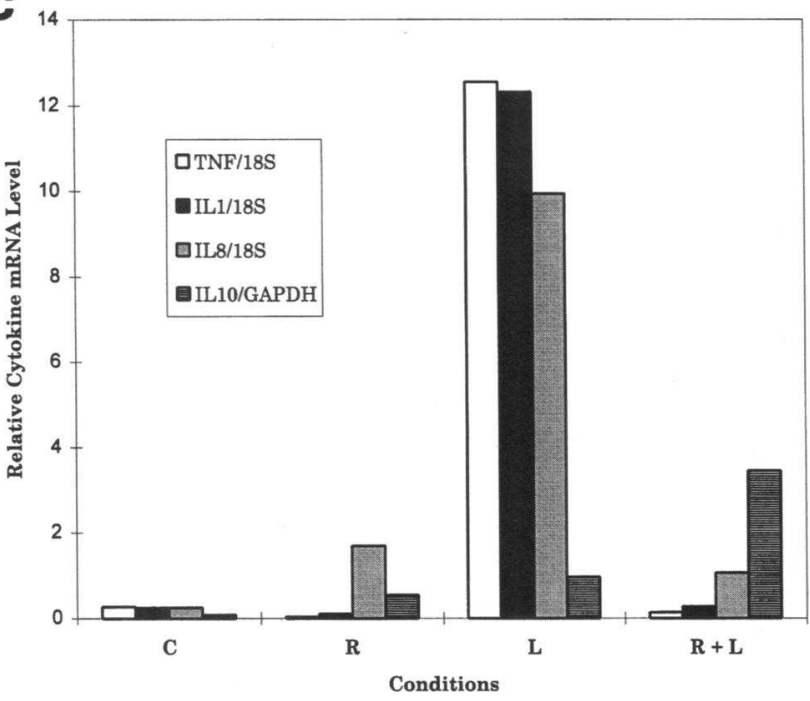

induction of IL-8 by RSV (10). We therefore focused on the kinetics of expression of IL-8 and IL-10 from pooled RNA from three donors. Due to the limited numbers of alveolar macrophages obtained from these donors, kinetics were analyzed by the sensitive method of semiquantitative RT-PCR. Alveolar macrophages were exposed to LPS, RSV, and RSV + LPS ( same doses as used previously) for 0,6 , and $12 \mathrm{~h}$ after stimulation. Transcripts for IL-8, IL-10, and HPRT, as a housekeeping gene, were determined by RT-PCR from purified, pooled RNA (500 ng/reaction determined spectrophotometrically). PCR products, analyzed by agarose gel electrophoresis, were amplified in parallel from the same RT reaction as a function of condition and time. Fig. $3(A)$ shows combined results expressed as the ratio of IL-8/HPRT (left) and IL-10/HPRT (right) from three separate RT-PCR amplifications of pooled RNA from these donors (mean \pm SD). LPS yielded maximal levels of IL-8 and IL-10 at $6 \mathrm{~h}$. RSV had a minor effect on IL8 levels at all time points compared to LPS. RSV stimulated $\mathrm{IL}-10$ transcripts as potently as LPS at $6 \mathrm{~h}$ and caused a sustained increase through $12 \mathrm{~h}$. RSV + LPS yielded lower IL-8
B

C $\mathrm{R}$ L $\mathrm{R}+\mathrm{L}$

IL-10

GAPDH

Figure 2. (A) Northern blot analysis of steady state levels of TNF- $\alpha$, IL$1 \beta, \mathrm{IL}-8$, and $18 \mathrm{~S}$ rRNA at $24 \mathrm{~h}$ after stimulation. Total RNA harvested from eight donors was purified, pooled, quantitated spectrophotometrically, and electrophoresed on $0.8 \%$ (wt/vol) agarose-formaldehyde gels. RNA was blotted to Genescreen membranes by capillary blot then probed sequentially with ${ }^{32} \mathrm{P}-\mathrm{cDNA}$ probes for TNF- $\alpha, \mathrm{IL}-1 \beta, \mathrm{IL}-8$, and $18 \mathrm{~S}$ rRNA. $C$, medium controls; $R$, RSV; $R+L$, RSV + LPS; $B$, blank; $L$, LPS alone at doses and times indicated in Fig. 1. (B) Northern blot analysis of steady state levels of IL-10 and GAPDH from pooled RNA (five donors) harvested from alveolar macrophages. Northern blots were probed with ${ }^{32} \mathrm{P}-\mathrm{cDNA}$ probes for IL-10 (top), then stripped and reprobed for GAPDH (bottom). Legends are the same as described in $A$. (C) Densitometry ratios of TNF- $\alpha$, IL- $1 \beta$, and IL- 8 to $18 \mathrm{~s}$ rRNA and IL-10 to GAPDH. Legends are the same as in $(A)$.

transcripts at $6 \mathrm{~h}$ compared to LPS alone. In contrast, these combined stimuli yielded maximal IL-10 levels at $12 \mathrm{~h}$ that were $\sim$ twofold increased compared to LPS- or RSV-activated cells. Thus, RSV and RSV + LPS did not stimulate IL-8 as potently as LPS alone. RSV and RSV + LPS did yield a timedependent increase in IL-10 transcripts. At $24 \mathrm{~h}$ after stimulation, RT-PCR of RNA yielded IL-8 levels that were higher ( $\sim$ threefold) in LPS- versus RSV- and RSV + LPS-stimulated cells (Fig. $3 B$, representative results from a single donor) compared to HPRT indicating that the transcript levels determined by this method paralleled results seen with Northern analysis.

$I L-10$ effects on alveolar macrophage $I L-1 \beta$ and $I L-8$ expression. To directly examine whether IL-10 could negatively regulate cytokine production, the effects of RSV-infected alveolar macrophage supernatants, or authentic recombinant IL-10, on alveolar macrophage IL- $\beta$ and IL-8 expression were assessed. Alveolar macrophages from two donors were stimulated with LPS $(10 \mu \mathrm{g} / \mathrm{ml})$ and incubated with medium alone, medium supplemented with uninfected or RSV-infected alveolar macrophage supernatants for $24 \mathrm{~h}$. IL- $1 \beta$ accumulation in super- 


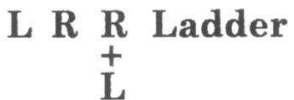

A

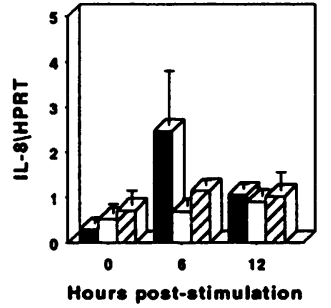

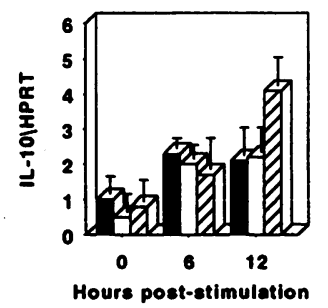

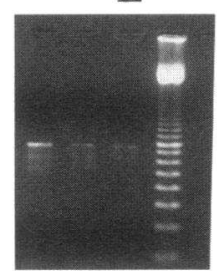

HPRT

IL-8

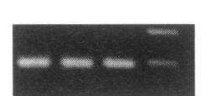

Figure 3. IL-8 and IL-10 transcript accumulation from alveolar macrophages. $(A)$ The ratio of IL-8/HPRT (left) ( 28 and 24 cycles, respectively) and IL-10/ HPRT (right) ( 30 and 24 cycles, respectively) after RTPCR amplification performed as described in Methods from pooled RNA from three donors at the indicated times after stimulation. Results shown are mean \pm SD from three separate RT-PCR reactions from the pooled RNA from these donors

-, LPS; $\square$, RSV; $\square$ RSV + LPS. (B) IL-8 (top) and HPRT (bottom) transcript levels determined by RT-PCR (28 and 24 cycles, respectively) from a single donor reproduced in a second donor. $L, \mathrm{LPS} ; R, \mathrm{RSV} ; R+L, \mathrm{RSV}+\mathrm{LPS} ;$ Ladder, molecular weight markers.

natants was then determined by ELISA (Table II). IL- $1 \beta$ levels from cells incubated with medium or those supplemented with uninfected alveolar macrophage supernatants $(1: 4$, vol/vol) were higher than cells incubated with RSV-infected alveolar macrophage supernatants $(1: 4, \mathrm{vol} / \mathrm{vol})$. Addition of a neutralizing antibody to IL-10 at the time of addition of RSVinfected supernatants completely reversed these effects (Table II). Addition of recombinant IL-10 $(5 \mathrm{ng} / \mathrm{ml})$ completely suppressed IL-1 $\beta$ accumulation which was again reversed by antiIL-10. In addition, higher volumes of RSV-infected alveolar macrophage supernatants yielded increased inhibition (not shown). RSV-infected alveolar macrophage supernatants (1:4, $\mathrm{vol} / \mathrm{vol}$ ) also suppressed IL-8 accumulation by LPS-stimulated alveolar macrophages by $72 \pm 11 \%$ (mean $\pm \mathrm{SD}, n=2)$, which again was completely reversed by anti-IL-10 (not shown). Thus, RSV stimulates IL-10 expression by alveolar macrophages that can inhibit early cytokine expression through an apparent autocrine mechanism.

RSV stocks did contain IL-6 at levels of $320 \pm 40 \mathrm{pg} / \mathrm{ml}$ which could potentially alter the levels of these cytokines. How-

Table II. Effects of RSV-infected Alveolar Macrophage Supernatants on IL-1 $\beta$ Production by LPS-stimulated Alveolar Macrophages

\begin{tabular}{|c|c|c|c|}
\hline \multicolumn{2}{|l|}{ LPS-stimulated alveolar macrophage } & \multicolumn{2}{|c|}{$\mathrm{IL}-1 \beta$} \\
\hline Condition $\ddagger$ & Anti-IL-10 & Donor 1 & Donor 2 \\
\hline & & $p g / m l^{*}$ & $p g / m l^{*}$ \\
\hline+ medium & - & 1,422 & 1,543 \\
\hline+ uninfected supernatant $(1: 4 \mathrm{vol} / \mathrm{vol})$ & - & 1,561 & 1,473 \\
\hline + RSV-infected supernatant $(1: 4 \mathrm{vol} / \mathrm{vol})$ & - & 962 & 1,141 \\
\hline + RSV-infected supernatant $(1: 4 \mathrm{vol} / \mathrm{vol})$ & + & 1,726 & 1,854 \\
\hline$+\mathrm{IL}-10(5 \mathrm{ng} / \mathrm{ml})$ & - & ND & ND \\
\hline$+\mathrm{IL}-10(5 \mathrm{ng} / \mathrm{ml})$ & + & 1,378 & 1,423 \\
\hline
\end{tabular}

* Values are means of duplicate samples. ${ }^{\ddagger}$ Alveolar macrophages were stimulated with LPS $(10 \mu \mathrm{g} / \mathrm{ml})$ for $2 \mathrm{~h}$ then washed and placed for 22 $\mathrm{h}$ in fresh medium, or medium supplemented with uninfected or RSVinfected alveolar macrophage supernatants, rIL-10, or neutralizing antibody to IL-10 (Anti-IL-10) (500 neutralizing U/ml) as indicated. ND, not detectable within the sensitivity of the assay $(24 \mathrm{pg} / \mathrm{ml})$. ever, addition of recombinant IL-6 at $450 \mathrm{pg} / \mathrm{ml}$ to alveolar macrophages stimulated with LPS had no detectable effects on IL- $1 \beta$ production whereas addition of $450 \mathrm{ng} / \mathrm{ml}$ inhibited by $84 \pm 13 \%$ (mean $\pm S D$, two separate donors). Because RSV-infected alveolar macrophages have been shown to produce IL- 6 at levels of $\sim 10 \mathrm{ng} / 10^{6}$ cells ( 10$)$, we assessed IL- $1 \beta$ production in the presence of an mAb to IL- 6 at levels sufficient to neutralize $75 \mathrm{ng} / \mathrm{ml}$ of IL- 6 bioactivity. IL- $1 \beta$ production by RSV-infected or LPS-activated alveolar macrophages did not differ by $>18 \pm 11 \%$ from cells not exposed to anti-IL-6 ( $n$ $=2$, separate donors). Thus, IL-10 appeared to primarily account for the suppression of IL- $\beta$ and IL-8 production by RSVinfected alveolar macrophages.

2-5A-dependent RNase L expression by alveolar macrophages. Previous studies have indicated that IL-10 can decrease cytokine levels through induction of an undefined endoribonuclease that degrades cytokine mRNA transcripts $(31,32)$. TNF- $\alpha$ (or IFN) in concert with viral intermediates serve as the necessary signals to stimulate the expression and activation of the 2-5A-dependent RNase L (8). This endoribonuclease degrades single-stranded RNA with preference for UU and UA sequences and could potentially account for the decreased cytokine transcripts observed in RSV-infected alveolar macrophages. Expression of 2-5A-dependent RNase $\mathrm{L}$ by alveolar macrophages were examined by Western blots after exposure of these cells to medium alone (uninfected control, $C$ ), RSV $(R)$, LPS $(L)$, and RSV + LPS $(R+L)$ (same doses as used above) (Fig. 4). Cells exposed to medium or LPS ( $C$ and $L$, respectively) exhibited nearly undetectable levels of 2-5Adependent RNase L, while RSV and RSV + LPS potently

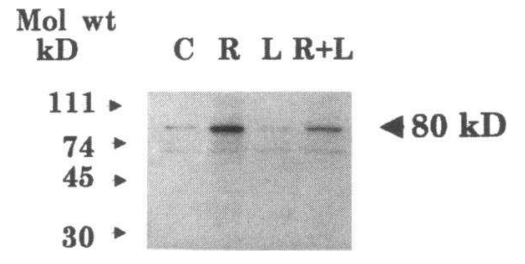

Figure 4. Western blot of 2-5A-dependent RNase $\mathrm{L}$ from lysates of alveolar macrophages. Lysates ( $75 \mu \mathrm{g} /$ lane) from alveolar macrophages exposed to medium controls $(C), \operatorname{RSV}(R)$, LPS

$(L)$, and RSV + LPS $(R+L)$ were analyzed by Western blots probed with an $\mathrm{mAb}$ to $2-5 \mathrm{~A}$-dependent $\mathrm{RNase} \mathrm{L}$ as described in Methods. Molecular weight markers are indicated at the left. Results shown are from a single donor and were replicated in a second donor. 
induced this enzyme ( $R$ and $R+L$, respectively). These results were reproduced in two separate experiments. Thus, RSV induces the expression of this, and perhaps other, endoribonucleases that may function to regulate the accumulation of cytokine mRNA transcripts critical to an effective immune response.

\section{Discussion}

RSV is the major pathogen of infant's lungs that causes damage by pathogenic mechanisms only partially understood (1). RSV infects and replicates rapidly in respiratory airway epithelial cells as well as alveolar macrophages $(21,22)$. A short replication cycle may allow the virus to elude cell-mediated and/or humoral responses regulated, in part, by macrophage function $(5,33,34)$. It has been shown that RSV directly alters alveolar macrophage expression of cytokines and major histocompatibility molecules $(6,7,9,10,21)$. Damaged, virus-infected cells could yield additional activating stimuli for macrophages (35). The studies reported here were designed to determine the effects of RSV on alveolar macrophage basal and activated (LPS) expression of cytokines which may offer insights into pathogenesis. Here, we demonstrate that RSV differentially stimulates human alveolar macrophage expression of cytokines and potently stimulates IL-10. IL-10 suppresses the production of IL$1 \beta$ and IL- 8 and thus may interfere with the establishment of an effective immune response to this virus.

A previous study demonstrated that human alveolar macrophages respond to exogenous $\mathrm{IL}-10$ with altered immunological functions (36), but direct studies of IL-10 production by human alveolar macrophages have not been reported. It has been shown previously that RSV transiently increases TNF- $\alpha$ expression by alveolar macrophages after in vitro infection $(9,10)$. We extended those previous studies in several important ways. $(a)$ RSV infection selectively stimulated TNF- $\alpha$, IL-10, and 2-5Adependent RNase $\mathrm{L}$ protein expression by human alveolar macrophages but did not stimulate secretion of IL- $1 \beta$ and actually slightly suppressed IL-8 (Fig. 1). (b) RSV induced only a minor increase in the mRNA levels of TNF- $\alpha$, IL- $1 \beta$, and IL8 at $24 \mathrm{~h}$ after infection while LPS markedly stimulated each of these cytokines. Kinetics of transcript accumulation indicated that RSV leads to a lesser and more delayed increase in IL-8 compared to LPS. (c) RSV increased IL-10 protein expression as assessed by Western blots and increased secretion as potently as LPS by ELISA quantitation. This was paralleled by increased mRNA levels at $6 \mathrm{~h}$ and sustained through $24 \mathrm{~h}$ after stimulation (Fig. 2). (d) Alveolar macrophages costimulated with RSV + LPS demonstrated decreased mRNA transcripts and protein production of TNF- $\alpha, \mathrm{IL}-1 \beta$, and IL- 8 but synergistically increased IL-10 levels compared to cells stimulated with LPS or RSV separately. (e) Finally, RSV-infected alveolar macrophage supernatants and recombinant IL-10 inhibited IL- $1 \beta$ and IL8 production by LPS-stimulated cells, and this inhibition was neutralized by anti-IL-10. Combined, these results indicate that RSV subverts the sustained production of IL- $1 \beta$ and IL-8 and may attenuate expression of TNF- $\alpha$ relative to LPS.

Prior studies have indicated that IL-10 induces degradation of TNF- $\alpha$ and IL- $1 \beta$ transcripts in murine macrophages (31). In contrast, studies with human monocytes demonstrate that IL10 induces degradation of IL- 6 transcripts but interferes with TNF- $\alpha$ and IL- $1 \beta$ at the level of transcription (32). No prior studies have addressed the mechanism of IL-10 regulation of cytokine expression by human alveolar macrophages. Kinetic studies reported here, and previously $(9,10)$, demonstrate that RSV induces a rapid but transient accumulation of TNF- $\alpha$ and IL-8 mRNA. However, transcript and protein levels of both of these cytokines were far less than those seen with LPS-activated cells. Surprisingly, cells costimulated with RSV + LPS showed a clear dichotomy in cytokine accumulation yielding suppressed levels of TNF- $\alpha$, IL- $1 \beta$, and IL- 8 mRNA and protein but markedly enhanced levels of IL-10 compared to LPS-activated cells. RSV + LPS interacted to yield high levels of IL-10 but it is not yet clear why these levels did not completely suppress TNF$\alpha$, IL- $1 \beta$, and IL-8. Perhaps cells activated by LPS accumulate these cytokines before RSV induces sufficient IL-10 to be completely suppressive. Kinetic results (Fig. 4) lend support to this hypothesis. RSV stocks did contain IL-6 at levels too low ( 320 $\mathrm{pg} / \mathrm{ml}$ ) to suppress IL- $1 \beta$ production by LPS-activated alveolar macrophages, although high levels of recombinant IL-6 (450 $\mathrm{ng} / \mathrm{ml}$ ) were inhibitory. IL-6 is produced by RSV-infected alveolar macrophages (10), however, addition of high levels of a neutralizing antibody to IL- 6 did not alter the level of IL- $1 \beta$ produced by LPS-activated alveolar macrophages. The mechanism by which RSV interacts with activated macrophages to suppress production of early cytokines yet increase IL-10 expression has not yet been examined due to the limited number of cells recovered by bronchoalveolar lavage from these normal donors $\left(11 \pm 3 \times 10^{6}\right.$ cells, $\left.n=20\right)$. The use of human macrophage cell lines, where cell numbers are not limiting, may prove useful for examination of these potential mechanisms.

We did demonstrate that RSV infection, and not LPS stimulation, induced the production of an endoribonuclease with preference for UU and UA sequences (8) (Fig. 4). The 2-5Adependent $R$ Nase $L$ is induced and activated by two requisite signals, i.e., induction of the protein itself by IFN and production of the activator $2-5 \mathrm{~A}$ by the TNF/IFN-induced $2-5 \mathrm{~A}$ synthetase and double-stranded RNA $(8,37,38)$. The 2-5A-activated $R$ Nase $L$ then functions as a potent antiviral enzyme degrading viral and cellular RNA ( 8 and references therein). The 2-5A-dependent RNase L may have a role in restricting RSV replication in human alveolar macrophages based on the following findings. Alveolar macrophages support efficient RSV replication for 24-72 $\mathrm{h}$ which thereafter declines by $>50$ fold (23). RSV-infected alveolar macrophages produce low levels of TNF- $\alpha$ as shown here and previously $(9,10)$, but addition of exogenous TNF- $\alpha$ markedly restricts RSV replication in these cells (21). Furthermore, RSV does not induce type I IFN production as do other respiratory viruses $(12,39)$. RSV and, less potently, RSV + LPS stimulated alveolar macrophages to increase expression of 2-5A-dependent RNase L (Fig. 4) whereas LPS alone was not stimulatory. However, LPS did induce high levels of TNF- $\alpha$, a cytokine previously shown to induce 2-5A synthetase yielding 2-5A which then activates the 2-5A-dependent RNase L $(37,38)$. It is possible that LPS induction of TNF- $\alpha$ serves to stimulate 2-5A synthetase while RSV induces 2-5A dependent RNase $\mathrm{L}$. Thus cells costimulated with RSV + LPS could have higher levels of the activated 25A-dependent RNase L. The activated 2-5A-dependent RNase $\mathrm{L}$ may degrade viral and cytokine mRNA. The Northern blot results and transcript levels shown in Figs. 2 and 3 are consistent with this hypothesis. However, the level of induction of 25A-dependent RNase L may be inadequate to yield detectable 
degradation of abundant RNA species such as $18 \mathrm{~S}$ ribosomal RNA levels, HPRT, or GAPDH transcripts (constitutively expressed), at least through $24 \mathrm{~h}$. Because alveolar macrophages do not proliferate, direct examination of the role of 2-5A-dependent RNase $\mathrm{L}$ in restricting RSV replication or degradation of cytokine transcripts using strategies such as dominant negative mutants of 2-5A-dependent RNase L (40) are not yet possible.

The role of IL-10 in viral infections is only partially understood. IL-10 is expressed by Epstein-Barr-transformed lymphocytes and may have a proximal role in establishing the latent infection characteristic of this virus (17). Vaccinia virus engineered to express IL-10 yields a selective stimulation of cytotoxic $\mathrm{T}$ lymphocytes and natural killer cells that could potentially facilitate latent viral infection (41). IL-10 is expressed by lymph node cells in murine models after experimental infection with influenza (42). Recently, murine studies suggest that a formalin-inactivated RSV vaccine primes production of IL-10 and IL-4 after RSV infection which yields enhanced pulmonary histopathology (43). Here, we demonstrated in human cells that RSV potently enhanced IL-10 production which functioned biologically to inhibit the expression of critical immunoregulatory cytokines.

These results confirm previous studies of TNF- $\alpha$ and IL- $1 \beta$ expression by alveolar macrophages infected with RSV in vitro or in vivo $(6,7,9,10)$ but contrast with a prior study indicating that RSV increased alveolar macrophage production of IL-8 protein (10). That study found that RSV-exposed alveolar macrophages accumulate low levels of IL-8 in supernatants ( $>100$ $\mathrm{ng} / 10^{6}$ cells), levels far less than the constitutive levels reported here and by other authors $(25,26)$ and far less than levels found in alveolar macrophages after simple adherence to plastic (29). In addition, the RSV $\mathrm{A}_{2}$ strain used in those studies was propagated in HEp 2 cells, whereas we used RSV $A_{2}$ strain (R. Chanock, National Institutes of Health, Bethesda, MD) that was plaque-purified and propagated in CV-1 cells, perhaps yielding virus stocks differing in biologic function. However, we did find that RSV yielded a slight increase in IL-8 mRNA transcripts (Fig. 2), consistent with that prior study (10), without yielding an increase in secreted IL-8.

Phagocytosis of pathogens, as well as production of immunoregulatory cytokines, serve as critical macrophage functions in their sentinel role of protecting the host against invading pathogens $(33,34)$. Viruses have evolved mechanisms to subvert these macrophage defenses. RSV avoids phagocytic mechanisms by spreading from cell to cell after fusion and syncytial formation (1). In addition, RSV does not stimulate a sustained expression of the antiviral cytokines TNF- $\alpha$ and IFN that could restrict viral replication $(9,12,39)$. Furthermore, although RSV induces expression of immunoregulatory cytokines, it simultaneously stimulates production of an IL-1 inhibitor (44). Here, we found that RSV directly stimulated IL-10 expression and secretion by alveolar macrophages which functioned to suppress early cytokine production by activated macrophages. These findings suggest that IL-10 may have a critical pathogenic role in the incomplete immune response to RSV.

\section{Acknowledgments}

The authors thank Genentech (San Francisco, CA) for the kind gift of TNF- $\alpha$. The excellent technical assistance of Mannish Dadhania, Husam Ghanaim, Allen Fields, and Amy Hochadel are gratefully acknowledged.
This work was supported by the National Institutes of Health R29 HL-46396, the Thrasher Research Fund, the Helen M. Baker Research Fund (J. R. Panuska), the Research Service of the Veterans Administration (J. A. Rankin), and supported, in part, by Specialized Centers of Research HL 37117.

\section{References}

1. McIntosh, K., and R. M. Chanock. 1990. Respiratory syncytial virus. In Virology, 2nd ed. edited by B. N. Field, D. M. Knipe, et al. Raven Press, Ltd., New York, 1045-1072.

2. Crowe, J. E., Jr., B. R. Murphy, R. M. Chanock, R. A. Williamson, C. F. Barbas III, and D. R. Burton. 1994. Recombinant human respiratory syncytia virus (RSV) monoclonal antibody Fab is effective therapeutically when introduced directly into the lungs of RSV-infected mice. Proc. Natl. Acad. Sci. USA 91:1386-1390.

3. Tristram, D. A., R. C. Welliver, C. K. Mohar, D. A. Hogerman, S. W Hildreth, and R. Paradiso. 1993. Immunogenicity and safety of respiratory syncytial virus subunit vaccine in seropositive children 18-36 months old. J. Infect. Dis. 167:191-195.

4. Heilman, C. A. 1990. Respiratory syncytial and parainfluenza viruses. $J$. Infect. Dis. 161:402-406.

5. Unanue, E. R., and J. C. Cerottini. 1989. Antigen presentation. FASEB (Fed. Am. Soc. Exp. Biol.) J. 3:2496-2502.

6. Panuska, J. R., M. I. Hertz, H. Taraf, A. Villani, and N. M. Cirino. 1992 Respiratory syncytial virus infection of alveolar macrophages in adult transplant patients. Am. Rev. Respir. Dis. 145:934-939.

7. Midulla, F., A. Villani, J. R. Panuska, I. Dab, J. K. Kolls, R. Merolla and $R$. Ronchetti. 1993. Respiratory syncytial virus lung infection in infants: immunoregulatory role of infected alveolar macrophages. J. Infect. Dis. 168:1515-1519.

8. Zhou, A., B. A. Hassel, and R. H. Silverman. 1993. Expression cloning of 2-5A-dependent RNase: a uniquely regulated mediator of interferon action. Cell. 72:753-765.

9. Panuska, J. R., F. Midulla, N. M. Cirino, A. Villani, I. A. Gilbert, E. R. McFadden, and Y. T. Huang. 1990. Virus induced alterations in macrophage production of tumor necrosis factor and prostaglandin $\mathrm{E}_{2}$. Am. J. Physiol. (Lung Cellular and Molecular Physiol.). 259:L396-L402.

10. Becker, S., J. Quay, and J. Soukup. 1991. Cytokine (tumor necrosis factor, IL-6, and IL-8) production by respiratory syncytial virus-infected human alveolar macrophages. J. Immunol. 147:4307-4312.

11. Salkind, A. R., J. E. Nichols, and N. J. Roberts, Jr. 1991. Suppressed expression of ICAM-1 and LFA-1 and abrogation of leukocyte collaboration after exposure of human mononuclear leukocytes to respiratory syncytial virus in vitro. J. Clin. Invest. 88:505-511.

12. Roberts, N. J., J. Hiscott, and J. Signs. 1992. The limited role of the human interferon system response to respiratory syncytial virus challenge: analysis and comparison to influenza virus challenge. Microb. Pathog. 12:409-414.

13. Viera, P., R. de Waal Malefyt, M. N. Dang, K. E. Johnson, R. Kastelein D. F. Fiorentino, J. E. d Vries, M. G. Roncarolo, T. R. Mosmann, and K. W. Moore. 1991. Isolation and expression of human cytokine synthesis inhibitory factor cDNA clones: homology to Epstein-Barr virus open reading frame BCRF1. Proc. Natl. Acad. Sci. USA. 88:1172-1178.

14. Bogdan, C., Y. Vodovotz, and C. Nathan. 1991. Macrophage deactivation by interleukin 10. J. Exp. Med. 174:1549-1555.

15. Fiorentino, D. F., A. Zlotnik, T. R. Mosmann, M. Howard, and A. O'Garra 1991. IL-10 inhibits cytokine production by activated macrophages. J. Immunol. 147:3815-3822.

16. Malefyt, R. W., J. Abrams, B. Bennett, C. G. Figdor, and J. E. de Vries 1991. Interleukin 10 (IL-10) inhibits cytokine synthesis by human monocytes: an autoregulatory role of IL-10 produced by monocytes. J. Exp. Med. 174:12091220.

17. Stewart, J. P., and C. M. Rooney. 1992. The interleukin-10 homolog encoded by Epstein-Barr virus enhances the reactivation of virus-specific cytotoxic $T$ cell and HLA-unrestricted killer cell responses. Virology. 191:773-782.

18. Strieter, R. M., S. W. Chensue, M. A. Basha, T. J. Standiford, J. P. Lynch III, M. Baggiolini, and S. L. Kunkel. 1990. Human alveolar macrophage gene expression of interleukin- 8 by tumor necrosis factor- $\alpha$, lipopolysaccharide, and interleukin-1 $\beta$. Am. J. Respir. Cell Mol. Biol. 2:321-326.

19. Baggiolini, M., A. Walz, and S. L. Kunkel. 1989. Neutrophil-activating peptide-1/interleukin 8, a novel cytokine that activates neutrophils. J. Clin. Invest. 84:1045-1049.

20. Welliver, R. C., D. T. Wong, M. Sun, E. Middleton, Jr., R. S. Vaughan, and P. L. Ogra. 1981. The development of respiratory syncytial virus-specific IgE and the release of histamine in nasopharyngeal secretions after infection. 1981. N. Engl. J. Med. 305:841-846.

21. Cirino, N. M., J. R. Panuska, A. Villani, H. Taraf, N. Rebert, R. Merolla, 
P. Tsivitse, and I. A. Gilbert. 1993. Restricted replication of respiratory syncytial virus in human alveolar macrophages. J. Gen. Virol. 74:1527-1537.

22. Merolla, R., N. A. Rebert, P. T. Tsiviste, S. P. Hoffman, and J. R. Panuska 1995. Respiratory syncytial virus replication in human lung epithelial cells: inhibition by tumor necrosis factor $\alpha$ and interferon $\beta$. Am. J. Resp. Crit. Care Med. (In press).

23. Panuska, J. R., N. M. Cirino, F. Midulla, J. E. Despot, E. R. McFadden Jr., and Y. T. Huang. 1990. Productive infection of isolated human alveolar macrophages by respiratory syncytial virus. J. Clin. Invest. 86:113-119.

24. Chomczynski, P., and N. Sacchi. 1987. Single-step method of RNA isolation by acid guanidium thiocyanate-phenol-chloroform extraction. Anal. Biochem. 162:156-159.

25. Rankin, J. A., I. Sylvester, S. Smith, T. Yoshimura, and E. J. Leonard. 1990. Macrophages cultured in vivo release leukotriene $B_{4}$ and neutrophil attractant/activation protein (interleukin 8 ) sequentially in response to stimulation with lipopolysaccharide and zymosan. J. Clin. Invest. 86:1556-1564.

26. Sylvester, I., J. A. Rankin, T. Yoshimura, S. Tanaka, and E. J. Leonard. 1990. Secretion of neutrophil attractant/activation protein by lipopolysaccharidestimulated lung macrophages determined by both enzyme-linked immunosorbent assay and N-terminal sequence analysis. Am. Rev. Respir. Dis. 141:683-688.

27. Elias, J. A., T. Zheng, O. Einarsson, M. Landry, T. Trow, N. A. Rebert, and

J. R. Panuska. 1994. Epithelial interleukin 11: regulation by cytokines, respiratory syncytial virus, and retinoic acid. J. Biol. Chem. 269:22261-22268.

28. Dong, B., and R. H. Silverman. 1995. 2-5A-dependent RNase molecules dimerize during activation by 2-5A. J. Biol. Chem. 270:4133-4137.

29. Standiford, T. J., S. L. Kunkel, K. Kasahara, M. J. Milia, M. W. Rolfe and R. M. Strieter. 1991. Interleukin-8 gene expression from human alveolar macrophages: the role of adherence. Am. J. Respir. Cell Mol. Biol. 5:579-585.

30. Metinko, A. P., S. L. Kunkel, T. J. Standiford, and R. M. Strieter. 1992 Anoxia-hyperoxia induces monocyte-derived interleukin-8. J. Clin. Invest. 90:791-798.

31. Bogdan, C., J. Paik, Y. Vodovtz, and C. Nathan. 1992. Contrasting mechanisms for suppression of macrophage cytokine release by transforming growth factor- $\beta$ and interleukin-10. J. Biol. Chem. 267:23301-23308.

32. Wang, P., P. Wu, M. I. Siegel, R. W. Egan, and M. B. Billah. 1994. IL 10 inhibits transcription of cytokine genes in human peripheral blood mononuclear cells. J. Immunol. 15:811-816.
33. Fels, A., and Z. A. Cohn. 1986. The alveolar macrophage. J. Appl. Physiol. 60:353-369.

34. Nathan, C. F. 1987. Secretory products of macrophages. J. Clin. Invest. 79:319-326.

35. Kelley, J. 1990. Cytokines of the lung. Am. Rev. Respir. Dis. 141:765791.

36. Nabioullin, R., S. Sone, K. Mizuno, S. Yano, Y. Nishioka, T. Haku, and T. Ogura. 1994. Interleukin-10 is a potent inhibitor of tumor cytotoxicity by human monocytes and alveolar macrophages. J. Leukocyte Biol. 55:437-442.

37. Mestan, J., M. Brockhaus, H. Kirchner, and H. Jacobsen. 1988. Antiviral activity of tumor necrosis factor. Synergism with interferons and induction of oligo-2',5'-adenylate synthetase. J. Gen. Virol. 69:3113-3120.

38. Wong, G. H. W., and D. V. Goeddel. 1986. Tumor necrosis factor $\alpha$ and $\beta$ inhibit virus replication and synergize with interferons. Nature (Lond.). 323:819-822.

39. Hall, C. B., R. G. Douglas, Jr., R. L. Simons, and J. M. Geiman. 1978 Interferon production in children with respiratory syncytial, influenza, and parainfluenza virus infections. J. Pediatr. 93:28-32.

40. Hassel, B. A., A. Zhou, C. Sotomayer, A. Maran, and R. H. Silverman. 1993. A dominant negative mutant of 2-5A-dependent RNase suppresses antiproliferative and antiviral effects of interferon. EMBO (Eur. Mol. Biol. Organ.) J. 12:3297-3304.

41. Kurilla, M. G., S. Swaminathan, R. W. Welsh, E. Kieff, and R. R. Brutkiewicz. 1993. Effects of virally expressed interleukin 10 on vaccinia virus infection in mice. J. Virol. 67:7623-7628.

42. Sarawar, S. R., and P. C. Doherty. 1994. Concurrent production of interleukin-2, interleukin-10, and gamma interferon in the regional lymph nodes of mice with influenza pneumonia. J. Virol. 68:3112-3118.

43. Connors, M., N. A. Giese, A. B. Kulkarni, C.-Y. Firestone, H. C. Morse III, and B. R. Murphy. 1994. Enhanced pulmonary histopathology induced by respiratory syncytial virus (RSV) challenge of formalin-inactivated RSV-immunized BALB/c mice is abrogated by depletion of interleukin-4 (IL-4) and IL-10. J. Virol. 68:5321-5325.

44. Salkind, A. R., D. O. McCarthy, J. E. Nichols, F. M. Domurat, E. E Walsh, and N. J. Roberts, Jr. 1991. Interleukin-1-inhibitor activity induced by respiratory syncytial virus: abrogation of virus-specific and alternate human lymphocyte proliferative responses. J. Infect. Dis. 163:71-77. 